\title{
INTRINSIC PATHWAY-DEPENDENT ACTIVATED CLOTTING TIME IS NOT RELIABLE FOR MONITORING ANTICOAGULATION DURING CARDIOPULMONARY BYPASS IN NEONATES
}

\author{
Y. J. Gu, MD, ${ }^{\mathrm{a}}$ R. J. Huyzen, MD, ${ }^{\mathrm{b}}$ and W. van Oeveren, MD, ${ }^{\mathrm{a}}$ Groningen, The Netherlands
}

The conventional activated clotting time (ACT) stimulated by celite is often prolonged during neonatal or pediatric cardiopulmonary bypass operations. ${ }^{1,2}$ This prolonged ACT may lead to insufficient use of heparin during bypass and result in serious consequences such as intravascular coagulation after the operation. ${ }^{3}$ Dilution of the clotting factors because of high-degree hemodilution during bypass is often blamed for the prolongation of ACT, ${ }^{2,4}$ but it is still unknown whether the total clotting capacity in the circulating blood is similarly affected by the extreme hemodilution. Because the celite ACT is a clotting test dependent on the intrinsic pathway, we postulate that it is the intrinsic pathway (rather than the extrinsic and the common pathways) that fails to respond properly under highdegree hemodilution during neonatal bypass operations.

As a first step, we studied the in vitro effect of dilution on celite ACT by using heparinized blood taken from 10 adults having coronary artery bypass. The samples were taken after a $300 \mathrm{IU} / \mathrm{kg}$ dose of bovine heparin was given before the start of bypass. These patients received no drugs known to affect clotting and had a normal clotting profile before the operation. Blood samples were diluted in the laboratory to $25 \%$, $50 \%$, and $75 \%$ with saline solution or were left undiluted as control samples. Three different types of stimuli were used to initiate clotting: celite (final concentration $3 \mathrm{mg} / \mathrm{ml}$ ) stimulating clotting through the intrinsic pathway, rabbit brain thromboplastin (final concentration $4 \mathrm{mg} / \mathrm{ml}$ ) through the extrinsic pathway, and high-dose thrombin (final concentration $9 \mathrm{U} / \mathrm{ml}$ ) through the common pathway. All measurements were performed with a Hemochron 8000 machine (International Technidyne Co., Edison, N.J.). An ACT longer than 1000 seconds was stopped and recorded as 1000 seconds. In blood samples stimulated by celite, ACT was prolonged significantly when the blood was diluted to $75 \%$ compared with the ACT of control samples ( $p<$ 0.01 ), whereas in samples stimulated by thromboplastin no significant change was observed. Furthermore, in blood samples stimulated by thrombin a significant reduction of $\mathrm{ACT}$ was found in proportion to the dilution of blood $(p<0.01$, Table I). These results

From the Department of Cardiothoracic Surgery and Anesthesiology ${ }^{\mathrm{b}}$ University Hospital, Groningen, The Netherlands.

Accepted for publication May 18, 1995.

J Thorac Cardiovasc Surg 1996;111:677-8

Copyright (C) 1996 by Mosby-Year Book, Inc.

$0022-5223 / 96 \$ 5.00+0 \quad \mathbf{1 2 / 5 4 / 6 6 3 3 1}$ suggest that it is the intrinsic pathway but not the extrinsic pathway and common pathway that is impaired to cause clotting in the test tubes under extreme hemodilution. These results also suggest that fibrinogen is not a limiting factor during extreme dilution if clotting is triggered by either the extrinsic pathway or the common pathway.

Clinically, we compared the celite ACT with the high-dose thrombin time (Hemochron machine; International Technidyne) during neonatal cardiopulmonary bypass $(n=10)$ after approval by the hospital ethical committee and written informed consent from the parents. These newborn infants had an average age of 8 days (1 to 17 days) and a mean body weight of $3.6 \mathrm{~kg}$ (3.1 to $4.5 \mathrm{~kg}$ ). Before bypass, anticoagulation was achieved by a $300 \mathrm{IU} / \mathrm{kg}$ dose of bovine heparin and a further $1000 \mathrm{IU}$ in the prime solution. The extracorporeal circuit was primed with Ringer's solution and human albumin with additional red blood cell concentrates. The average hemoglobin level at 30 minutes of bypass was $52.8 \pm 8.8 \mathrm{gm} / \mathrm{L}$. Almost all the celite ACTs were longer than 1000 seconds during bypass, whereas the concentration of heparin (measured by antifactor $X$ assay) was gradually declining. By contrast, the highdose thrombin time shortened gradually toward the end of bypass (Table II).

Celite ACT is based on clot formation through the intrinsic clotting pathway, which is dependent on several clotting factors in the early clotting cascade. ${ }^{5}$ The baseline levels of intrinsic clotting factors, such as factor XII and factor XI, are much lower in neonates than in adults. ${ }^{6}$ Moreover, the degree of hemodilution during bypass is higher in neonates than in adults. ${ }^{7}$ Thus the intrinsic clotting pathway in neonates is too weak to be triggered in the extremely diluted blood, so that the celite ACT is prolonged and less heparin is needed. On the other hand, the metabolism of heparin during bypass is more rapid in children than in adults, ${ }^{2}$ and these neonates, especially those with cyanosis, are likely to have extensive exposure of blood in the thoracic cavity, which is known to further consume heparin. ${ }^{8}$ All these factors taken together, these neonates are facing a great risk of receiving insufficient anticoagulation during bypass if their condition is monitored by the celite ACT.

Thus the conventional celite ACT, in which clotting is stimulated from the intrinsic pathway, is not a reliable test for monitoring anticoagulation for neonatal or pediatric cardiopulmonary bypass during a high degree of hemodilution. We recommend that tests stimulating the common clotting pathway, such as the high-dose thrombin time or other reliable methods, be used to prevent the empiric use of heparin for neonates. 
Table I. In vitro effect of hemodilution on whole blood clotting time (seconds)

\begin{tabular}{lllrlr}
\hline & & \multicolumn{3}{c}{ Degree of hemodilution } \\
\cline { 5 - 6 } \multicolumn{1}{c}{ Stimulus } & Pathway & Controls & $25 \%$ & $50 \%$ & $75 \%$ \\
Celite & Intrinsic & $459 \pm 75$ & $442 \pm 67$ & $488 \pm 94$ & $951 \pm 154^{*}$ \\
Thromboplastin & extrinsic & $294 \pm 29$ & $251 \pm 21$ & $277 \pm 34$ & $355 \pm 61$ \\
Thrombin & common & $165 \pm 51$ & $113 \pm 58$ & $91 \pm 34$ & $55 \pm 19$ \\
\hline
\end{tabular}

Values are expressed as mean \pm standard deviation.

*In 9 of 10 samples clotting time was more than 1000 seconds.

Table II. Clinical observation in neonates undergoing cardiac operations

\begin{tabular}{|c|c|c|c|c|c|c|}
\hline & $\begin{array}{c}\text { After } \\
\text { heparinization }\end{array}$ & $\begin{array}{c}5 \min \\
C P B\end{array}$ & $\begin{array}{c}30 \min \\
C P B\end{array}$ & $\begin{array}{c}60 \mathrm{~min} \\
C P B\end{array}$ & $\begin{array}{c}90 \mathrm{~min} \\
C P B\end{array}$ & $\begin{array}{l}\text { End } \\
C P B\end{array}$ \\
\hline ACTc (sec) & $669 \pm 233$ & $980 \pm 63^{*}$ & $992 \pm 63^{*}$ & $995 \pm 15^{*}$ & $1000 \pm 0$ & $774 \pm 214$ \\
\hline HiTT (sec) & $168 \pm 58$ & $163 \pm 80$ & $132 \pm 31$ & $132 \pm 53$ & $118 \pm 53$ & $95 \pm 30$ \\
\hline Heparin $(\mathrm{IU} / \mathrm{ml})$ & $2.7 \pm 0.4$ & $1.2 \pm 0.5$ & $1.1 \pm 0.5$ & $1.3 \pm 0.4$ & $1.2 \pm 0.5$ & $0.8 \pm 0.3$ \\
\hline
\end{tabular}

Values are expressed as mean \pm standard deviation. $A C T C$, Celite activated clotting time; HiTT, high-dose thrombin time; CPB, cardiopulmonary bypass. *In 9 of 10 samples ACTc was greater than 1000 seconds.

\section{REFERENCES}

1. Horkay F, Martin P, Rajah SM, Walker DR. Response to heparinization in adults and children undergoing cardiac operations. Ann Thorac Surg 1992;53:822-6.

2. Kriesmer P, Payne NR, Tessmer J, Uden DL. Activated clotting time tests with heparinase in the management of pediatric patients on cardiopulmonary bypass. ASAIO J 1993;39:942-5

3. Gravlee GP, Haddon WS, Rothberger HK, et al. Heparin dosing and monitoring for cardiopulmonary bypass: a comparison of techniques with measurement of subclinical plasma coagulation. J THORAC CARDIOVASC SURG 1990;99:518-27.

4. Culliford AT, Gitel SN, Starr N, et al Lack of correlation between activated clotting time and plasma heparin during cardiopulmonary bypass. Ann Surg 1981;193:105-11.
5. Huyzen RJ, Harder MP, Gallandat Huet RCG, et al. Alternative anticoagulation monitoring during cardiopulmonary bypass in aprotinin treated patients. $\mathbf{J}$ Thorac Cardiovasc Anaesth 1994;8:153-6.

6. Andrew M, Paes B, Milner R, et al. Development of the human coagulation system in the full-term infant. Blood 1987;70:165-72.

7. Kern FH, Morana NJ, Sears JJ, Hickey PR. Coagulation defects in neonates during cardiopulmonary bypass. Ann Thorac Surg 1992;54:541-6.

8. Tabuchi N, de Haan J, Boonstra PW, van Oeveren W. Activation of fibrinolysis in the pericardial cavity during cardiopulmonary bypass. J Thorac CARdiovasc Surg 1993;106:828-33.

\title{
THE USE OF BIOLOGIC GLUE FOR BETTER ADHESIONS BETWEEN THE SKELETAL MUSCLE FLAP AND THE MYOCARDIUM AND FOR INCREASING CAPILLARY INGROWTH
}

\author{
Valeri Chekanov, MD, PhD, Victor Nikolaychik, MD, PhD, and Guennady Tchekanov, MD, Milwaukee, Wis.
}

To date, dynamic cardiomyoplasty relies on use of a properly conditioned, adequately contracting autogenous muscle flap for the correction of myocardial insufficiency. Despite its advantages, cardiomyoplasty has some unresolved problems: (1) poor angiogenic potential of the ischemic, traumatized skeletal muscle and damaged myocardium and (2) incomplete contact between the mobile myocardial wall and the transplanted flap.

From the Milwaukee Heart Project, Milwaukee, Wis.

Received for publication July 19, 1995; accepted for publication Sept. 5, 1995.

J THORaC Cardiovasc Surg 1996;111:678-80

Copyright (C) 1996 by Mosby-Year Book, Inc.

$0022-5223 / 96 \$ 5.00+0 \quad \mathbf{1 2 / 5 4 / 7 1 0 5 9}$
These problems manifest themselves after the opertion. The vascular supply is not reintroduced until 6 to 8 months after the operation. Some patients have died of recurrent myocardial infarction 3 to 5 months after cardiomyoplasty, before a new blood supply from the skeletal muscle to the myocardium had been established. ${ }^{1,2}$ This is the situation that needs to be resolved. Cardiomyoplasty done with skeletal muscle can provide capillary ingrowth to the myocardium, but it may be too late for some patients.

A novel approach to resolving these problems involves "therapeutic angiogenesis." Nine weeks after a modified fibrin glue (containing endothelial cell growth factor) has been applied between the aorta and the left ventricular myocardium, angiographic and histologic investigations have shown newly grown vascular structures between 